\title{
Sensibilidade à secagem da matéria-prima cerâmica da Formação Corumbataí na região do Polo Cerâmico de Santa Gertrudes, SP
}

\section{(Raw ceramic material drying sensitivity from Corumbataí Formation in the Ceramic District of Santa Gertrudes, SP, Brazil)}

\author{
A. A. Azzi, M. Z. Curtolo, A. Zanardo \\ Departamento de Petrologia e Metalogenia, Instituto de Geociências e Ciências Exatas, UNESP, Av. 24 \\ A 1515, Rio Claro, SP 13506-900 \\ andrezzazzi@gmail.com,muri-lo-zaine@hotmail.com,azanardo@rc.unesp.br
}

\begin{abstract}
Resumo
As argilas provenientes da Formação Corumbataí são atualmente a principal fonte de matéria-prima para as indústrias do Polo Cerâmico de Santa Gertrudes. $73 \%$ das indústrias desse polo que utilizam o processo de secagem via seca são hoje alvo de crescente pressão dos órgãos de controle ambiental devido à emissão de partículas (poeira) associado ao processo de secagem da matériaprima. Neste trabalho, foram realizados quatro diferentes testes de secagem em três tipos de matéria-prima (D, I e M) da Formação Corumbataí, com umidades naturais iniciais de $8 \%, 18 \%$ e $19 \%$, respectivamente, para poder avaliar a sensibilidade à secagem. Dentre os testes analisados neste trabalho estão o processo natural de secagem ao sol, secagem ao vento, secagem ao sol combinado a uma corrente de vento, e secagem ao sol com matéria-prima previamente umedecida em água corrente. Os testes foram ainda correlacionados à análise termogravimétrica. A análise por difração de raios X, juntamente com as análises química e petrográfica mostrou que as amostras D, I e M contêm predominantemente filossilicatos 2:1 como illitas (25-30\%) e esmectitas (15-25\%), e em menor quantidade caulinita $(0-15 \%)$ e clorita $(0-5 \%)$. Os resultados dos experimentos de secagem associados à mineralogia mostram que entre $100^{\circ} \mathrm{C}$ e $200{ }^{\circ} \mathrm{C}$ nos gráficos de termogravimetria pode indicar de modo rápido a sensibilidade à secagem que o material apresenta, uma vez que a maior perda de umidade obtida nesta faixa indica a maior quantidade de minerais do grupo das esmectitas, que por sua vez conferem ao material menor sensibilidade à secagem. Além disso, os procedimentos de secagem natural sugerem que secar separadamente a matéria-prima pode resultar em maior eficiência do processo de secagem.
\end{abstract}

Palavras-chave: Polo Cerâmico de Santa Gertrudes, matéria-prima cerâmica, Formação Corumbataí, secagem, argilas.

\begin{abstract}
The clays from the Corumbatai Formation are the major source of raw ceramic materials for industries in the Ceramic District of Santa Gertrudes, SP, Brazil. 73\% of those industries that use the dry grinding process are being targeted of increasing pressure from the environmental control agencies due to particle emission (dust) in the air associated with the drying process of raw materials. In this paper, four different types of experiments were performed on three different types of raw-material ( $D, I$ and $M)$ from the Corumbatai Formation, with initial moisture contents of $8 \%, 18 \%, 19 \%$, respectively, to evaluate the drying sensitivity of these samples. The tests conducted were drying by sunlight, drying by wind, drying by sunlight combined with an air stream, and drying by sunlight the samples previously moistened in flowing water. The tests were correlated with thermogravimetric analyses. The $X$-ray diffraction analysis along with the chemical and petrographic analysis has shown that samples D, I and M contain, mainly, phyllosilicates 2:1, such as illite (25-30\%) and smectite (15-25\%), and fewer amounts of kaolinite (0-15\%) and chlorite (0-5\%). The results of the drying experiments associated with the mineralogy of the samples showed that the thermogravimetric curves in the 100 ${ }^{\circ} \mathrm{C}-200{ }^{\circ} \mathrm{C}$ range may indicate in a faster way the materials drying sensitivity, once the major moisture loss obtained in this range indicates the largest amount of smectite, which gives a lower drying sensitivity to the material. Moreover, the dry route procedures suggest that drying the materials separately may improve the drying process results.
\end{abstract}

Keywords: Ceramic District of Santa Gertrudes, raw ceramic material, Corumbatai Formation, drying, clays.

\section{INTRODUÇÃO}

No interior do Estado de S. Paulo localiza-se o principal aglomerado mínero-cerâmico do país conhecido como Polo Cerâmico de Santa Gertrudes (PCSG). Sua localização abrange os municípios paulistas de Rio Claro, Santa Gertrudes, Araras, Ipeúna, Cordeirópolis, Charqueada, Piracicaba, Limeira e Iracemápolis (Fig. 1), e possui aproximadamente 30 minerações, 43 áreas de beneficiamento (sobretudo pátios de homogeneização e secagem de argila) e 34 indústrias cerâmicas especializadas em pisos e revestimentos [1]. O PCSG representa fundamental importância no desenvolvimento socioeconômico dos seus municípios, estado e país, sendo responsável por cerca de $60 \%$ da produção de pisos e revestimentos cerâmicos do Brasil, e $86 \%$ da produção do estado de S. Paulo 
[1]. Atualmente, as cerâmicas contam com avançados equipamentos de tecnologia com capacidade de produção acima de $500 \mathrm{mil} \mathrm{m}^{2} /$ mês, dentre os quais, alguns chegam a possuir capacidade instalada superior a 1 milhão de $\mathrm{m}^{2}$ [2]. Esse expressivo volume da produção de pisos tem provocado uma elevada e crescente demanda por matérias-primas. No setor extrativo mineral admite-se um consumo anual de matérias-primas superior a 8 milhões de toneladas, que são supridas por cerca de 30 minerações [2]. Das indústrias do PCSG, $73 \%$ utilizam o processo de fabricação via seca, que produz pisos e revestimentos cerâmicos classificados como BIIb (absorção de água entre 6 e 10\%). As demais indústrias fabricam produtos de maior valor agregado e utilizam o processo de moagem via úmida [3]. A fabricação via seca é resultado de um processo inovador que oferece grande vantagem competitiva às indústrias do PCSG por ser economicamente mais vantajosa do que a via úmida (processo tradicional utilizado mundialmente). Na fabricação via seca utiliza-se apenas matéria-prima da Formação Corumbataí extraída na região [4], e o processo de moagem e granulação é mais simples e menos dispendioso em consumo de energia térmica e elétrica [1]. A etapa de secagem da matéria-prima é realizada ao sol, em grandes áreas abertas denominadas pátios de secagem. Nos pátios de secagem, as argilas são espalhadas ao chão para o procedimento de cominuição e revolvimento, buscando a homogeneização e eliminação do excesso de umidade até valores inferior a 5,5\% [5]. Na etapa seguinte, essa massa é transportada para aindústria, onde é efetuada a moagem a seco, que consiste em moagem primária em moinho de martelo, moagem secundária em moinho pendular, peneiramento, umidificação e estocagem em silos [6]. Entretanto, referente ao processo via seca, existe

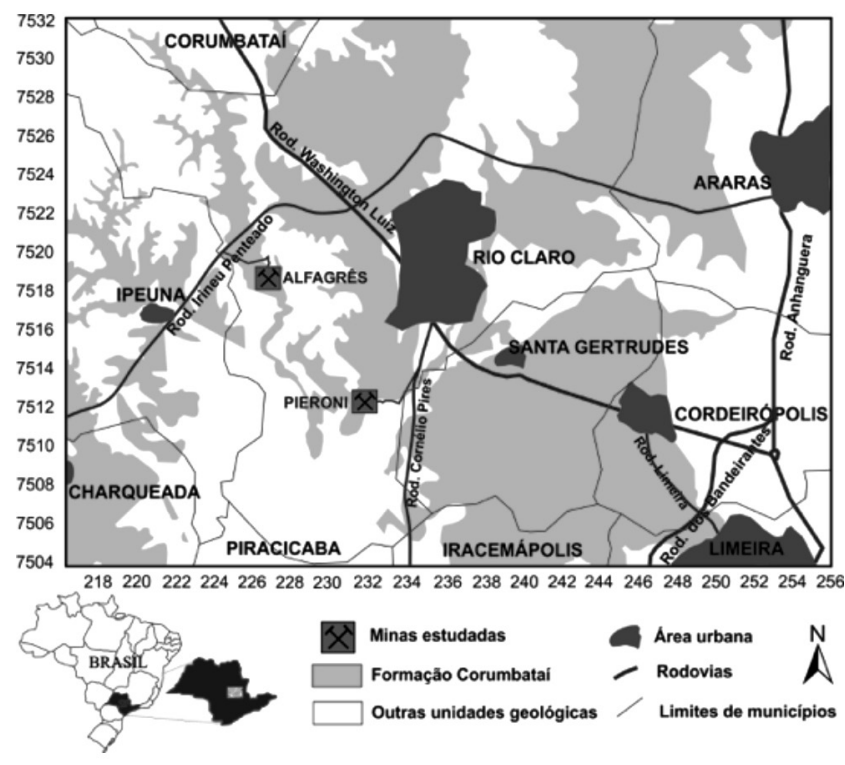

Figura 1: Área de abrangência do PCSG destacando a localização das minerações Alfagrês e Pieroni onde foram coletados os materiais estudados [7].

[Figure 1: Coverage area of CDSG highlighting the location of Alfagrês and Pieroni mines where the material was collected [7].] uma crescente pressão das agências de controle ambiental, para que as indústrias cerâmicas desenvolvam novos métodos de secagem para reduzir a emissão de particulados associado ao procedimento de secagem da matéria-prima e também ao transporte da mesma. As repetições diárias destas atividades acabam por afetar a qualidade do ar, as drenagens e a população nessa região. Devido à eminente proibição da etapa de secagem a céu aberto, nos pátios de secagem, é indispensável promover alternativas que atendam às necessidades das indústrias e que ao mesmo tempo minimizem os impactos negativos à população e ao meio ambiente. Perante a necessidade de se reduzir ao máximo o impacto ambiental decorrente das atividades de secagem da matéria-prima, o estudo da sensibilidade à secagem visa compreender o comportamento de algumas das matérias-primas cerâmicas utilizadas no polo de Santa Gertrudes, com o intuito de auxiliar no desenvolvimento de novos métodos de secagem que minimizem ou até mesmo eliminem a emissão de poeira. Obviamente, aspectos técnicos e econômicos precisam ser avaliados em estudos futuros.

\section{MATERIAIS E MÉTODOS}

A fabricação de pisos por via seca na região do PCSG tem como característica a utilização de diferentes tipos de matérias-primas da Formação Corumbataí para compor a massa cerâmica. Tais rochas compreendem argilitos siltosos/ siltitos argilosos classificados como duro, intermediário ou mole devido à resistência mecânica que as rochas apresentam. Nesse estudo foi coletado cada um dos três tipos de matéria-prima (duro, intermediário e mole). A escolha por essas amostras foi feita de acordo com a alta umidade para cada categoria e pela reconhecida dificuldade de secagem que apresentam. As amostras D (dura) e I (intermediária) foram extraídas da mina Alfagrês e a amostra M (mole), foi extraída da mina Pieroni. Ambas as minas estão localizadas no município de Rio Claro, SP, e geologicamente pertencente à porção basal da Formação Corumbataí.

Preparação das amostras: $35 \mathrm{~kg}$ de cada amostra (D, I e M) foram cominuídas a mão com o auxílio de um martelo, a fim de se obter fragmentos em torno de $2,5 \mathrm{~cm}$ e preservar a umidade natural dos materiais $(\mathrm{D}=8 \%, \mathrm{I}=18 \% \mathrm{e}$ $\mathrm{M}=19 \%$ ). A homogeneização foi feita utilizando o método de quarteamento, e posteriormente o material foi ensacado em porções de $1 \mathrm{~kg}$ em sacos plásticos devidamente vedados para preservar a umidade das amostras. Estes procedimentos foram feitos separadamente para os três materiais coletados.

Análise química: as amostras $\mathrm{D}$, I e $\mathrm{M}$, ainda naturalmente úmidas, foram enviadas à empresa Acme Analytical Laboratories Ltda. em Vancouver, Canadá, para a análise química dos elementos pelo método $4 \mathrm{~A}$ e 4B FullSuite em ICP-MS e fluorescência de raios X. A perda ao fogo foi calculada pela diferença de massa após aquecimento a $1000^{\circ} \mathrm{C}$.

Petrografia: fragmentos de rochas referentes aos três diferentes materiais (D, I e M), com consistência suficiente 
para possibilitar as atividades de laminação, foram selecionadas e encaminhadas para a preparação de seções delgadas com aproximadamente $30 \mu \mathrm{m}$ de espessura. As análises petrográficas foram realizadas em microscópio óptico monocular Leitz (Wetzlar, Sm - Lux Pol, com aumentos de 40x, 100x, 250x e 630x) e em microscópios binoculares Olympus D1600 e Zeiss XT200, utilizando o método de luz transmitida. Esse estudo permitiu a estimativa visual da porcentagem dos minerais presentes nas amostras.

Difração de raios $X$ : as amostras D, I e $\mathrm{M}$ na fração inferior a $2 \mu \mathrm{m}$ (separadas por decantação) foram preparadas para análise qualitativa, de forma orientada, em lâminas de vidro, das quais foram amostradas na forma natural, glicolada $(48 \mathrm{~h})$ e queimada $\left(550{ }^{\circ} \mathrm{C}\right.$ por $\left.2 \mathrm{~h}\right)$. As análises foram realizadas em difratômetro de raios X PANanlytical Empyrean, com radiação Cuk $\alpha$ (1,54056 $\AA$ ). A faixa de $2 \theta$ foi de $3^{\circ}$ a $40^{\circ}$, com passo de $15 \mathrm{~s}$ e tamanho do passo $0,02^{\circ}$. A corrente foi $30 \mathrm{~mA}$ e a voltagem $40 \mathrm{kV}$. Para a interpretação dos gráficos foi utilizado o software X'PertHighscore Plus e a base de dados ICDS.

Análise térmica: a análise termogravimétrica foi realizada em um equipamento TA Instr. 2690/DTA/DSC com analise simultânea em STA 449 F1 Jupiter (Netzsch) em atmosfera de ar $\left(50 \mathrm{~cm}^{3} \mathrm{~min}^{-1}\right)$, termopar tipo $\mathrm{S}$, cadinho de Pt-Ir, 30 mg de amostra, taxa de aquecimento $10{ }^{\circ} \mathrm{C} / \mathrm{min}$ na faixa 30 ${ }^{\circ} \mathrm{C}-1000{ }^{\circ} \mathrm{C}$. As análises foram feitas nas amostras D, I e M (fração total) e os resultados obtidos foram analisados no software Netzsch Proteus.

Secagem natural: para os testes de secagem natural, as amostras foram ensaiadas na fração inferior a $3 \mathrm{~cm}$, com o objetivo de simular o tamanho das partículas nos pátios de secagem. Na "secagem ao sol", $1 \mathrm{~kg}$ de cada material foi exposto à luz solar durante um período de 12 $\mathrm{h}$ (6:00 às 18:00). A umidade dos materiais, assim como a temperatura e a umidade do ar foram conferidos a cada $2 \mathrm{~h}$. A umidade das amostras foi obtida utilizando uma balança determinadora de umidade Ohaus MO200, programada na temperatura de $105{ }^{\circ} \mathrm{C}$ e tempo de análise de $5 \mathrm{~min}$. Para cada leitura, as amostras eram fragmentadas e passadas em peneira de $0,5 \mathrm{~mm}$, sendo utilizados $3,5 \mathrm{~g}$ de material. A temperatura e a umidade do ar foram medidas utilizando um termohigrógrafo. $\mathrm{Na}$ "secagem ao vento", utilizou-se um ventilador para gerar correntes de ar sobre as amostras, em condições laboratoriais, sem luz solar. $\mathrm{Na}$ "secagem sol+ vento" o ventilador foi direcionado as amostras em ambiente externo, contendo luz solar. O experimento "secagem água + sol" foi efetuado após submeter às amostras em água corrente durante cinco minutos para simular uma chuva rápida durante a secagem à luz solar. Esses experimentos foram realizados semana sim, semana não, ao longo de 6 meses (agosto a janeiro).

\section{RESULTADOS}

Análises química e mineralógica: os elementos maiores das amostras D, I e M estão apresentados na forma de óxidos na Tabela I. Os óxidos predominantes são $\mathrm{SiO}_{2}(62-65 \%)$,
$\mathrm{Al}_{2} \mathrm{O}_{3}(14-16 \%)$ e $\mathrm{Fe}_{2} \mathrm{O}_{3}(5-6 \%)$. Os valores de perda ao fogo são correlacionados às amostras que continham maior umidade natural (M, I e D respectivamente), mas devido aos procedimentos de preparação das amostras para a realização dos ensaios químicos, os valores de perda ao fogo $(8,6 \%$, $8 \%$ e $6,4 \%$ ) são diferentes da umidade natural que essas amostras exibiam quando coletadas em campo (19\%, 18\% e $8 \%$ ). A análise petrográfica mostra que a textura das amostras D, I e M é dominantemente composta por níveis pelíticos contendo filossilicatos. Os níveis psamíticos são menos frequentes e contêm principalmente quartzo e feldspatos na fração $<80 \mu \mathrm{m}$. A análise qualitativa dos minerais nas amostras D, I e M foi determinada através dos difratogramas (normal, glicolado e queimado) representados na Fig. 2. A análise quantitativa foi estimada pela correlação entre as análises químicas, porcentagem mineralógica estimada visualmente pela petrografia, e cálculos estruturais utilizando as fórmulas químicas dos minerais [8]. A amostra D apresenta aproximadamente 50\% argilominerais e 50\% minerais não argilosos. Os minerais s são: illita $(30 \%)$, esmectitas (15\%), clorita (5\%), quartzo (30\%), albita $(10 \%)$, feldspato potássico (5\%) e hematita (5\%). A amostra I possui aproximadamente $65 \%$ de argilominerais e $35 \%$ de minerais não argilosos, na seguinte proporção: illita (35\%), esmectita $(25 \%)$, caulinita $(5 \%)$, quartzo $(25 \%)$, feldspato potássico $(5 \%)$ e hematita (5\%).A amostra $\mathrm{M}$ apresenta as mesmas relações entre minerais argilosos e não argilosos que a amostra I, e também a mesma proporção dos minerais não argilosos. O que difere portanto a amostra $\mathrm{M}$ da amostra I é a quantidade dos minerais argilosos como apresentado a seguir: illita $(25 \%)$, esmectitas $(25 \%)$ e caulinita $(15 \%)$. A presença de ferro na forma de óxidos proporciona ao material uma coloração avermelhada. Pequenas quantidades de outros minerais como muscovita, biotita, adulária, fósseis silicosos, zircão, turmalina e apatita também foram encontrados. A amostra $\mathrm{D}$, devido à passagem de fluidos pelo material, apresenta tonalidades verdes e esbranquiçadas, que se destaca em meio a coloração predominantemente avermelhada. A maior proporção de fácies ricas em quartzo e a menor quantidade de filossilicatos colaboram com a maior resistência apresentada pela rocha D em comparação as amostras I e M.

O difratograma das amostras glicoladas indicam a presença de argilominerais expansivos (grupo das esmectitas). Picos em $7 \AA$ e entre 14 e $17 \AA$ desaparecem completamente nas amostras I e $\mathrm{M}$ no difratograma após $550{ }^{\circ} \mathrm{C}$, o que confirma a presença de caulinita e esmectita respectivamente. Já na amostra $\mathrm{D}$, um pico remanescente em $14 \AA$ confirma a presença de clorita. Os difratogramas das amostras D, I e M mostram que a presença de esmectitas na amostra I, é indicada por um pico de menor intensidade, porém mais aberto (entre 14 e $17 \AA$ ) evidenciando baixa cristalinidade relacionada a mudanças supérgenas. A amostra D, que está estratigraficamente localizada abaixo da amostra I, mostra que o pico da esmectita é mais agudo e de maior intensidade, reforçando o fato da amostra D (dura) estar menos intemperizada. Outro fator importante 
que reforça o grau de intemperismo nessas amostras são os dados obtidos na análise química. $\mathrm{O}$ indicativo do maior grau de intemperismo das amostras é correlacionado a uma série de dados como: menor porcentagem de $\mathrm{SiO}$ e álcalis, maior quantidade de $\mathrm{Al}_{2} \mathrm{O}_{3}$ e LOI, ausência de albita, baixo teor de feldspato potássico, maior quantidade de esmectitas e a formação de caulinita. Evidências que reforçam a maior influência da atividade intempérica na amostra $M$ (mole). Por sua vez, a amostra I, sendo mais mole que a amostra $\mathrm{D}$ e possuindo valores de álcalis e sílica inferior a amostra $\mathrm{D}$, e $\mathrm{Al}_{2} \mathrm{O}_{3}$ e LOI superior a amostra $\mathrm{D}$, se encontra mais intemperizada que a mesma. Para as amostras D, I e M os baixos valores de $\mathrm{Na}_{2} \mathrm{O}$ e $\mathrm{CaO}$ são atribuídos aos processos de alteração, pois esses óxidos são os primeiros a serem removidos pelo intemperismo, em função da mineralogia. Tais evidências confirmam os aspectos vistos em campo, onde as rochas foram classificadas conforme o grau de alteração [9].

Análise térmica: as análises térmicas (termogravimétrica e térmica diferencial- TG-ATD) foram realizadas para as amostras D, I e M, entre 25 e $997{ }^{\circ} \mathrm{C}$ (Fig. 3). A umidade adsorvida pelos argilominerais é quase que totalmente eliminada pelo aquecimento até $100{ }^{\circ} \mathrm{C}$. A partir desta temperatura, entre 100 e $200{ }^{\circ} \mathrm{C}$ têm-se a eliminação da água contida entre as camadas dos argilominerais [10]. Para as três amostras, as curvas TG-ATD mostraram que a primeira reação endotérmica teve seu máximo em aproximadamente $80{ }^{\circ} \mathrm{C}$, eliminando em torno de $1 \%$ de umidade na amostra D e $1,1 \%$ de umidade nas amostras I e M. É válido ressaltar que essa umidade não reflete a umidade inicial das amostras D, I e M $(8 \%, 17 \%$ e $19 \%)$ uma vez que as amostras foram previamente secadas e moídas para a realização desta análise. A perda de água intercamadas (entre 100 e $200{ }^{\circ} \mathrm{C}$ ) nas amostras D, I e $\mathrm{M}$ apresentam os respectivos valores de $0,9 \%, 1,1 \%$ e $1,2 \%$. Reações de desidroxilação, aparentemente, se iniciam em torno de $300{ }^{\circ} \mathrm{C}$ e exibem sua máxima curva endotérmica em aproximadamente $500{ }^{\circ} \mathrm{C}$ e $580{ }^{\circ} \mathrm{C}$ na amostra I e M e 550$580^{\circ} \mathrm{C}$ na amostra D. Esse duplo intervalo está relacionado à presença de mais de um argilomineral nessas amostras, tal como, illita, esmectita e caulinita (amostras I e M) eillita, esmectita e clorita (amostra D).

Experimento de secagem natural: os resultados obtidos nos testes de secagem realizados durante seis meses, sob diferentes condições, estão dispostos na Tabela II. Foram plotados os mais altos valores de umidade para o período, considerando assim as condições mais adversas, em cada um dos procedimentos. A umidade inicial das amostras D, I e M são respectivamente $8 \%, 18 \%$ e $19 \%$. Na "secagem ao

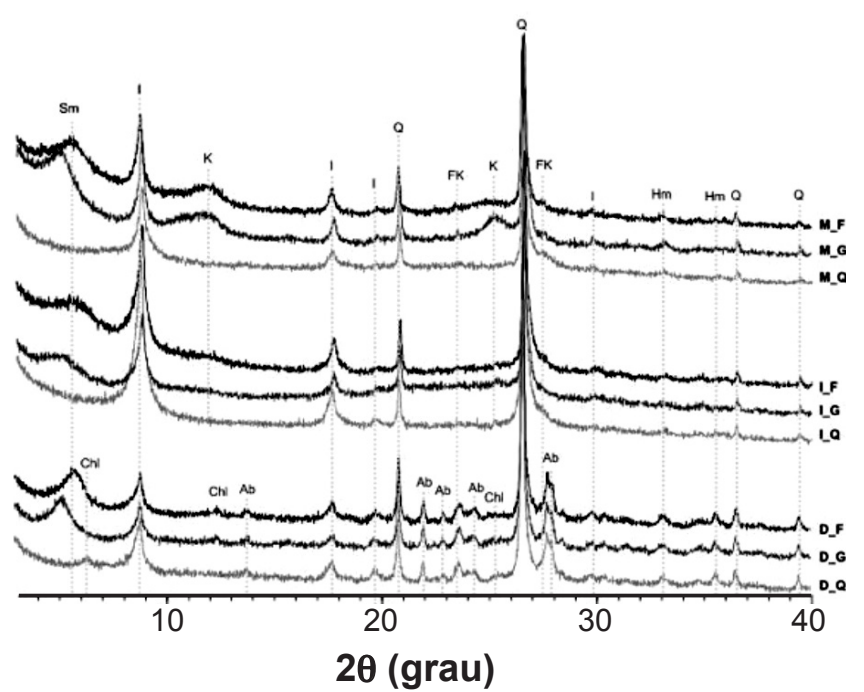

Figura 2: Difratogramas de raios X das amostras D, I e F. Sendo: F, fração fina; G, fração fina glicolada; Q, fração fina queimada; Sm, esmectita; I, illita; K; caulinita; Q, quartzo; FK, feldspato potássico; Hm, hematita; Chl, clorita; Ab, albita.

[Figure 2: X-ray diffraction patterns of samples D, I and M. F, fine fraction; $G$, glycol fine fraction; $Q$, burned fine fraction; $S m$, smectite; I, illite; K, kaolinite; Q, quartz; FK, potassium feldspar; $H$, hematite; Chl, chlorite; Ab, albite.]

sol" o material duro (D) seca rapidamente, atingindo 5\% de umidade logo às $10 \mathrm{~h}$ da manhã. $\mathrm{O}$ material intermediário (I) e mole (M)exigemum tempo de exposição maior e temperaturas mais altas para atingirem o teor de umidade desejado (5\%). Que em ambas as amostras ocorreu às 16:00. A "secagem ao vento" utilizando a corrente de argerada pelo ventilador e não expondo os materiais a luz solar, mostrou que não é eficiente o suficiente para retirar a umidade das amostras D, I e $\mathrm{M}$ em valores inferior a $5,5 \%, 11,5 \%$ e $8,7 \%$. A falta de poder calorífico não possibilitou penetrar a microporosidade das amostras e remover a umidade interna, secando apenas as camadas superficiais das partículas (umidade do ar de $50 \%$ e temperatura de $25{ }^{\circ} \mathrm{C}$, em média). $\mathrm{O}$ uso de uma corrente de ar, combinado com a luz solar (sol + vento), culminou em resultados satisfatórios, pois fez com que a amostra $\mathrm{D}$ atingisse o teor desejado na primeira verificação de umidade (8:00), levando então, menos de 2 $\mathrm{h}$ para atingir $5 \%$ de umidade, como mostrado na Tabela II. As amostras D e I atingiram a umidade desejada em menos de $6 \mathrm{~h}$, onde a verificação de umidade efetuada às 12:00 $\mathrm{h}$ acusou valores de umidade inferior a $4 \%$. Para o teste "água+sol" as amostras foram umedecidas por $5 \mathrm{~min}$ em água corrente e então colocadas sob o sol das 10:00 h para

Tabela I - Análises químicas de elementos maiores. [Table I - Chemical analysis of major elements.]

\begin{tabular}{ccccccccccccc}
\hline & $\mathrm{SiO}_{2}$ & $\mathrm{Al}_{2} \mathrm{O}_{3}$ & $\mathrm{Fe}_{2} \mathrm{O}_{3}$ & $\mathrm{Na}_{2} \mathrm{O}$ & $\mathrm{K}_{2} \mathrm{O}$ & $\mathrm{MgO}$ & $\mathrm{CaO}$ & $\mathrm{MnO}$ & $\mathrm{P}_{2} \mathrm{O}_{5}$ & $\mathrm{TiO}_{2}$ & LOI & TOTAL \\
\hline $\mathrm{D}$ & 65,47 & 13,96 & 5,07 & 1,36 & 3,41 & 2,42 & 0,90 & 0,06 & 0,17 & 0,58 & 6,4 & 99,8 \\
$\mathrm{I}$ & 63,16 & 15,30 & 5,85 & 0,38 & 3,86 & 2,20 & 0,24 & 0,06 & 0,07 & 0,65 & 8,0 & 99,8 \\
$\mathrm{M}$ & 62,74 & 16,53 & 6,24 & 0,08 & 2,98 & 1,67 & 0,16 & 0,05 & 0,07 & 0,68 & 8,6 & 99,8 \\
\hline
\end{tabular}



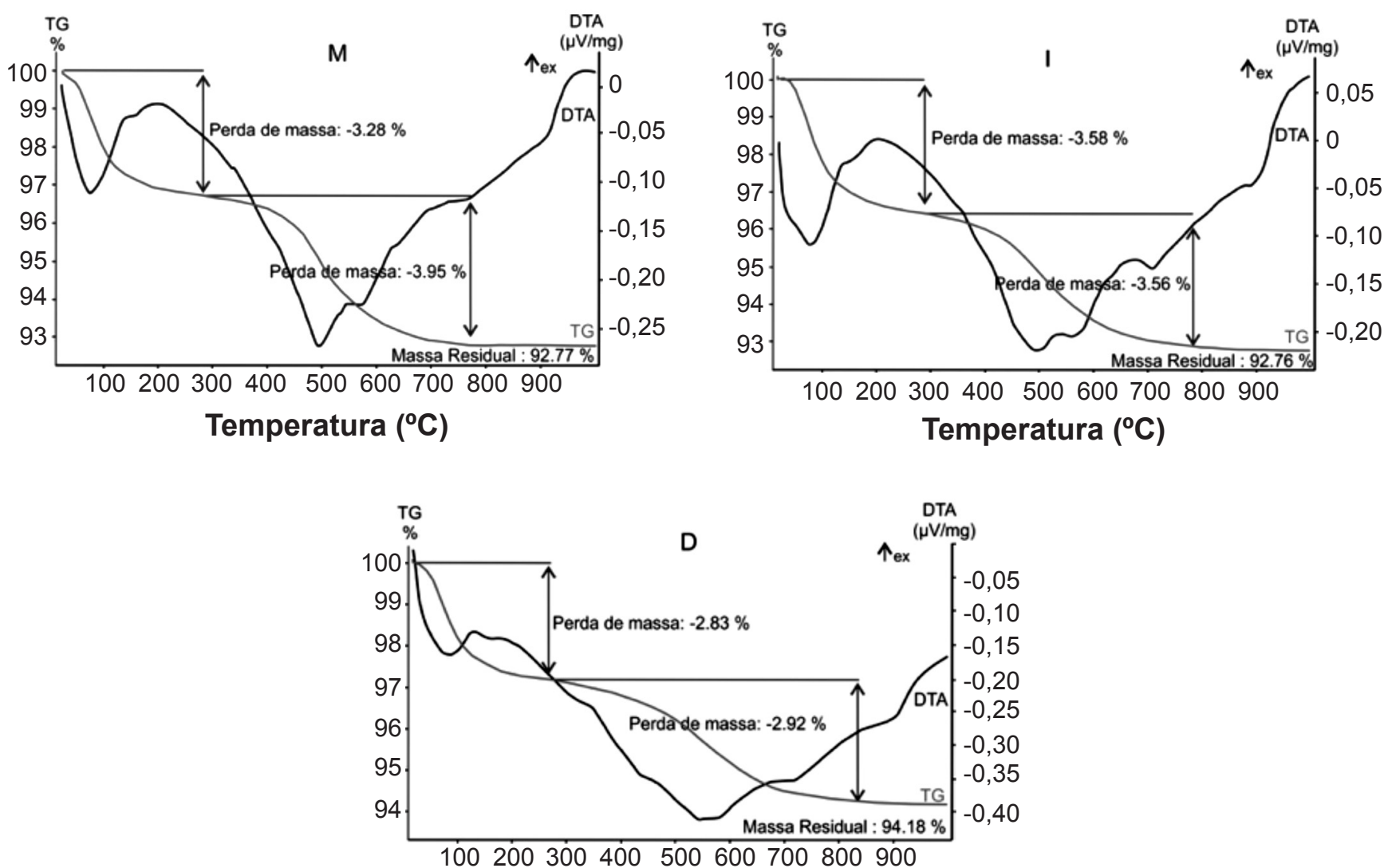

Temperatura $\left({ }^{\circ} \mathrm{C}\right)$

Figura 3: Curvas das análises térmicas ATD-TG para as amostras D, I e M, mostrando a perda de massa durante aquecimento entre $25^{\circ} \mathrm{C}$ e $997^{\circ} \mathrm{C}$.

[Figure 3: DTA-TG curves of samples D, I and M, showing the mass loss during heating between $25^{\circ} \mathrm{C}$ and $997^{\circ} \mathrm{C}$.]

Tabela II - Perda de umidade das amostras D, I e M, em diferentes experimentos.

[Table II - Humidity loss of samples D, I and $M$ in different experiments.]

\begin{tabular}{|c|c|c|c|c|c|c|c|c|}
\hline Amostra & experimento & $6: 00$ & $8: 00$ & $10: 00$ & $12: 00$ & $14: 00$ & $16: 00$ & 18:00 \\
\hline \multirow{4}{*}{$\mathrm{D}$} & Secagem ao sol & $*(\%)$ & 7,1 & 5 & 4,2 & 3,5 & 4 & 4,3 \\
\hline & Secagem ao vento & $*(\%)$ & 7,1 & 6,5 & 5,8 & 5,5 & 5,3 & 5,3 \\
\hline & Secagem sol + vento & $*(\%)$ & 5 & 3,7 & 3,1 & 3 & 3 & 3,3 \\
\hline & Secagem água + sol & $*(\%)$ & $*(\%)$ & 7,3 & 3,6 & 3,9 & - & - \\
\hline \multirow{4}{*}{ I } & Secagem ao sol & $*(\%)$ & 16,8 & 11,2 & 8,2 & 6 & 4,4 & 4,9 \\
\hline & Secagem ao vento & $*(\%)$ & 16,1 & 15,5 & 14,9 & 12 & 11,5 & 11,8 \\
\hline & Secagem sol + vento & $*(\%)$ & 11,1 & 7,9 & 3,8 & 3,8 & 3,8 & 4 \\
\hline & Secagem água + sol & $*(\%)$ & $*(\%)$ & 11,4 & 6,6 & 4,5 & - & - \\
\hline \multirow{4}{*}{ M } & Secagem ao sol & $*(\%)$ & 16,9 & 14,3 & 6,9 & 5,8 & 5 & 5,1 \\
\hline & Secagem ao vento & $*(\%)$ & 18,2 & 14,5 & 12,8 & 9,9 & 8,7 & 9,2 \\
\hline & Secagem sol + vento & $*(\%)$ & 13,8 & 8,3 & 3,1 & 3,1 & 3,3 & 4 \\
\hline & Secagem água + sol & $*(\%)$ & $*(\%)$ & 12,9 & 7,2 & 3,3 & - & - \\
\hline
\end{tabular}

*umidadae inicial - umidade não verificada

secarem. Nessas condições as amostras I e M atingiram o teor de 5\% de umidade em menos de quatro horas e a amostra $\mathrm{D}$ foi seca em menos de $2 \mathrm{~h}$. Molhar as amostras e colocá- las ao sol culminou na significante perda de umidade em um período de tempo menor. Tal melhoria pode ser diretamente correlacionada à quebra das partículas em fragmentos 

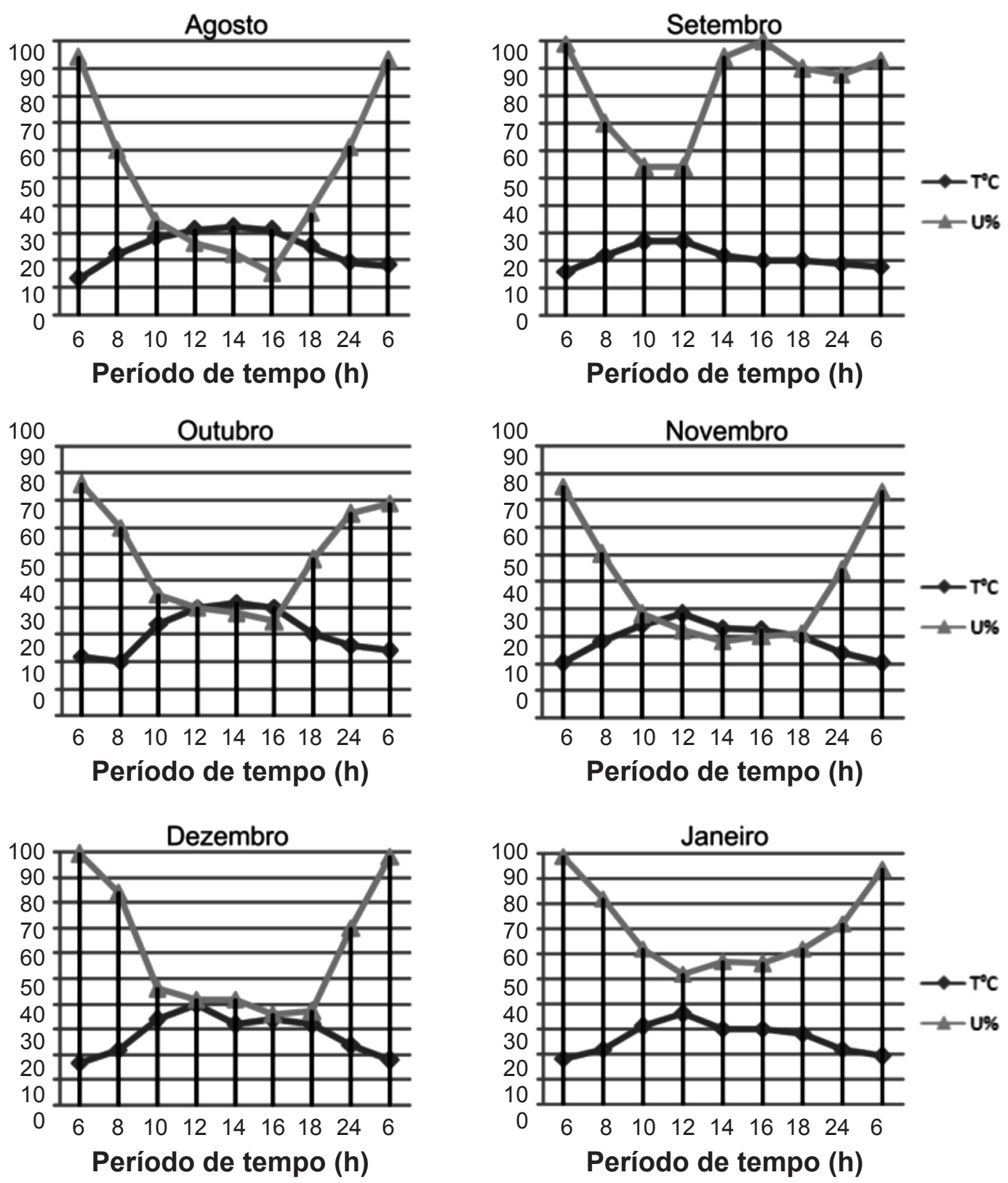

Figura 4: Média dos valores de umidade e temperatura obtidos durante os experimentos pelo termohigrógrafo. [Figure 4: Average of humidity and temperature values obtained during the experiments by thermohygrograph.]

menores, devido à retração do material na secagem, que de forma natural possibilitou uma maior superfície de contato, e tornou a secagem mais eficiente.

A fim de complementar os experimentos também foram realizadas medições de controle. Os materiais foram expostos ao ambiente durante a noite (00:00 às 6:00) como objetivo de determinar a reabsorção de umidade. Os resultados mostraram que os materiais reabsorveram até $2 \%$, chegando a apresentar valores em torno até $5,5 \%$ de umidade. Essa informação reforça, por exemplo, a não necessidade em secar as amostras em valores inferiores a 5\%. Outro fator importante foi ter feito a checagem de umidade nas partículas de fundo às 18:30 h. Logo após coletar as umidades das amostras no período das 18:00 h, foram feitas medições da umidade dos materiais da porção inferior, que não foram atingidos pelo sol. Para a amostra D não houve diferença de umidade, tendo a amostra de fundo às 18:30 $\mathrm{h}$ o mesmo valor de umidade das amostras de superfície as 18:00 h. No entanto, para as amostras I e M os fragmentos de rochas que permaneceram abaixo do restante do material, culminou em umidades de até $6 \%$ a mais que as amostras de superfície.

$\mathrm{O}$ registro do termohigrógrafo mostra que as secagens mais eficientes para este período do ano em 2012, ocorreram em Agosto, Outubro, Novembro e Dezembro, que são os meses com as melhores combinações entre umidades baixas e altas temperaturas. Essa relação promove um processo de secagem mais eficiente, principalmente entre às 10:00 e 16:00 h, como verificado nas curvas da Fig. 4. 


\section{DISCUSSÃO}

A determinação da sensibilidade à secagem possibilita prever o comportamento da rocha argilosa perante a secagem. Por exemplo, é de conhecimento geral que argilas com alta sensibilidade a secagem apresentam baixa retração linear, e argilas com baixa sensibilidade à secagem apresentam alta retração linear [10]. Baseado nos dados disponíveis para as argilas brutas (teor de umidade, retração linear, tempo e condições de secagem proporcionados a pisos verdes de alta qualidade), as argilas que continham minerais do grupo das esmectitas em sua composição apresentavam as piores taxas de secagem. A composição mineralógica das argilas mostra que, aquelas que apresentam a menor sensibilidade à secagem, contêm, principalmente, esmectitas. Uma quantidade maior de esmectita nas rochas causam a diminuição da sensibilidade à secagem. Esse fenômeno está associado a variação nos parâmetros cristalinos dos argilominerais expansivo [10]. Essa mudança nos parâmetros da rede cristalina leva, inevitavelmente, á uma retração durante a secagem que inicia-se em aproximadamente $100{ }^{\circ} \mathrm{C}$ e continua em maiores temperaturas. Se comparados a outros argilominerais como caulinitas e illitas, a rede cristalina desses minerais sofre variações desprezíveis devido à perda de umidade nas temperaturas normalmente utilizadas para secagem. Diferentes composições mineralógicas das amostras estudadas foram correlacionadas aos resultados das análises térmicas (Tabela. III).

A determinação da sensibilidade à secagem das argilas consiste na relação ente a quantidade de umidade liberada no aquecimento entre 100 e $200{ }^{\circ} \mathrm{C}$ [10]. A remoção da umidade intra-camadas absorvida nas esmectitas e em outros argilominerais começa a acontecer em temperaturas mais baixas, por exemplo, após o máximo pico endotérmico por volta de $80{ }^{\circ} \mathrm{C}$. O comportamento de secagem das argilas é altamente influenciado pela perda de umidade intra-camadas durante a secagem. Portanto, existe uma relação entre a quantidade de umidade perdida entre 100 ${ }^{\circ} \mathrm{C}$ e $200{ }^{\circ} \mathrm{C}$ e a menor ou maior quantidade de minerais do grupo da esmectita [10]. É suposto que a maior parte da umidade absorvida nas argilas é removida até $100^{\circ} \mathrm{C}$ e que essa umidade não possui efeito significante na determinação quantitativa da umidade intra-camadas liberada no intervalo de 100 a $200^{\circ} \mathrm{C}$. Assim, a análise da perda de umidade entre 100 e $200{ }^{\circ} \mathrm{C}$, quando medidos corretamente, é um método rápido baseado na composição mineralógica e na natureza físico-química das argilas, capaz de estimar suas respectivas sensibilidades à secagem [10].

\section{CONCLUSÕES}

$\mathrm{O}$ experimento de secagem natural mostrou na prática a sensibilidade à secagem das argilas $\mathrm{D}$, I e $\mathrm{M}$ que se correlacionaram com os valores de perda de umidade obtidos no gráfico de ATD-TG entre $100{ }^{\circ} \mathrm{C}$ e $200{ }^{\circ} \mathrm{C}$. A maior sensibilidade à secagem da amostra $\mathrm{D}$ reflete o curto tempo necessário de exposição ao sol que esta rocha necessita para atingir $5 \%$ de umidade. Já as amostras I e M possuem menor sensibilidade à secagem e necessitam de um tempo mais prolongado e mais energia para as amostras atingirem $5 \%$ de umidade. O conhecimento destas características é fundamental para a otimização da secagem ao sol, pois como foi verificado as rochas argilosas apresentam diferentes sensibilidades à secagem. Secar separadamente os diferentes tipos de matérias-primas é mais eficiente, do que quando misturado tipos diferentes de materiais, uma vez que rochas com maior sensibilidade à secagem podem acabar por atrapalhar as rochas com menor sensibilidade à secagem atingirem a umidade necessária para seguirem para a etapa de moagem. A menor sensibilidade à secagem está relacionada à quantidade de esmectitas, (quando maior a quantidade desses minerais, maior a dificuldade de secagem) e, para as matérias-primas da Formação Corumbatai, também ao grau de alteração do material (quanto maior a micro porosidade do material gerada por lixiviação supérgena ou hidrotermal, maior é a umidade natural e maior a dificuldade de secagem). O processo via seca no Polo Cerâmico de Santa Gertrudes necessita que as matérias-primas atinjam umidades inferiores a $5,5 \%$ para seguirem para a moagem. No entanto, não é necessário que o material atinja umidades inferiores a $5 \%$, pois estes irão reabsorver umidade do ambiente, o que fará com que eles atinjam valores em torno de $5 \%$ novamente, desperdiçando assim, tempo e energia. Cabe ressaltar que a umidade média de $5 \%$ envolvendo materiais de diferente sensibilidade á secagem, os fragmentos com maior quantidade de esmectita (menor sensibilidade a secagem) certamente estarão com umidade superior ao valor médio, podendo acarretar problemas na produção. Nesse sentido, secar separadamente os diferentes materiais que constituem a massa, além de evitar o potencial problema anteriormente mencionado, ainda otimiza a secagem no sentido de que os materiais com maior sensibilidade a

Tabela III - Composição mineralógica e perda de água intercamada entre 100 e $200{ }^{\circ} \mathrm{C}$.

[Table III - Mineralogical composition and interlayer water loss between 100 and $200^{\circ} \mathrm{C}$.]

Amostra Composição mineralógica

Perda de água

intercamada entre

\begin{tabular}{ccc} 
& & $100-200{ }^{\circ} \mathrm{C}$ \\
\hline D & Ilita (30\%), esmectita (15\%), quartzo, K-feldspato, albita e hematita. & $0,89 \%$ \\
I & Ilita (35\%), esmectita (25\%), caulinita (5\%), quartzo, K-feldspato, potássio e hematita. & $1,20 \%$ \\
M & Ilita (25\%), esmectita (25\%), caulinita (15\%), quartzo, K-feldspato, potássio e hematita. & $1,22 \%$ \\
\hline
\end{tabular}


secagem necessitam bem menos tempo de exposição ao sol. Finalmente, os experimentos mostraram que a maior superfície de contato das partículas melhora o desempenho da secagem. A umidificação prévia gerou a fragmentação do material e o aumento da porosidade, o que, assim como o vento, favoreceu o processo de secagem.

\section{AGRADECIMENTOS}

Os autores agradecem à Slovakia Academy of Sciences and Comenius University of Bratislava pelas análises termogravimétricas. Ao Dr. Rogers Rocha, Filipe Lima e Cibele Montibeller pela ajuda na coleta e preparação das amostras. A. Azzi é bolsista CAPES - Proc. BEX 2999-13-7.

\section{REFERÊNCIAS}

[1] IPT, Instituto de Pesquisas Tecnológicas do Estado de S. Paulo, "Formulação do plano diretor de mineração dos municípios de Santa Gertrudes, Cordeirópolis, Ipeúna, Iracemápolis e Rio Claro", (Rel. IPT 129345-205), IPT/ SDECT (2012) 273.
[2] M. Cabral Junior, C. T. C. Gamba, L. C. Tanno, A. S. Almeida, T. T. Cruz, Ceram. Ind. 18, 2 (2013) 10.

[3] R. R. Rocha, A. Zanardo, M. M. T. Moreno, Cerâmica 54 (2008) 332.

[4] M. M. T. Moreno, A. Zanardo, R. R. Rocha, C. D. Roveri, Cerâmica 58 (2012) 342.

[5] IPT, Instituto de Pesquisas Tecnológicas do Estado de S. Paulo, "Bases técnicas para o desenvolvimento da indústria mineral no Polo de Santa Gertrudes - SP", (Rel. IPT 64.402), IPT/SCTDET (2002) 92.

[6] A. C. A. Prado, A. Zanardo, M. M. T. Moreno, A. P. M. Menegazzo, Cerâmica 54 (2008) 467.

[7] S. R. Christofoletti, M. M. T. Moreno, Ceram. Ind. 16, 3 (2011) 35.

[8] W. A. Deer, R. A. Howie, J. Zussman, Minerais Constituintes das Rochas - Uma Introdução, Ed. Fundação Calouste Gulbenkian, Londres, Inglaterra (1966).

[9] L. H. Godoy, M. M. T. Moreno, A. Zanardo, Cerâmica 57 (2011) 478.

[10] V. P. Varlamov, L. A. Kroichuk, A. A. Toporkova, Ceramurgia Int. 2, 2 (1978) 98.

(Rec. 10/09/2014, Ac. 10/04/2015) 